\title{
Proteasome Inhibitors for the Treatment of Multiple Myeloma
}

\author{
Shigeki Ito \\ Hematology \& Oncology, Department of Internal Medicine, Iwate Medical University School of Medicine, \\ Yahaba-cho 028-3695, Japan; shigei@iwate-med.ac.jp; Tel.: +81-19-613-7111
}

Received: 27 December 2019; Accepted: 19 January 2020; Published: 22 January 2020

\begin{abstract}
Use of proteasome inhibitors (PIs) has been the therapeutic backbone of myeloma treatment over the past decade. Many PIs are being developed and evaluated in the preclinical and clinical setting. The first-in-class PI, bortezomib, was approved by the US food and drug administration in 2003. Carfilzomib is a next-generation PI, which selectively and irreversibly inhibits proteasome enzymatic activities in a dose-dependent manner. Ixazomib was the first oral PI to be developed and has a robust efficacy and favorable safety profile in patients with multiple myeloma. These PIs, together with other agents, including alkylators, immunomodulatory drugs, and monoclonal antibodies, have been incorporated into several regimens. This review summarizes the biological effects and the results of clinical trials investigating PI-based combination regimens and novel investigational inhibitors and discusses the future perspective in the treatment of multiple myeloma.
\end{abstract}

Keywords: multiple myeloma; proteasome inhibitors; bortezomib; carfilzomib; ixazomib

\section{Introduction}

Multiple myeloma (MM) remains an incurable disease. Over the last ten years, the availability of new drugs, such as the proteasome inhibitors (PIs), the immunomodulatory drugs (IMiDs), the monoclonal antibodies (MoAbs), and the histone deacetylase inhibitors, have greatly advanced the treatment and improved the survival of patients with MM [1-3]. Proteasome inhibition has emerged as a crucial therapeutic strategy in the treatment of MM. The first-in-class PI, bortezomib, was approved by the US food and drug administration (FDA) in 2003; it has contributed to the improvement in survival of MM patients [4]. Bortezomib is currently widely used not only for the patients with newly diagnosed but also relapsed and/or refractory MM. Recently, several second-generation PIs, including carfilzomib and ixazomib, have been introduced into clinical use. Carfilzomib is a peptide epoxyketone that binds irreversibly to the $\beta 5$ subunit of the constitutive proteasome and inhibits the chymotrypsin-like activity [5]. Carfilzomib was approved by the US FDA in 2012; it is indicated as a single agent, or in combination with dexamethasone $(\mathrm{Kd})$ or with lenalidomide plus dexamethasone $(\mathrm{KRd})$ for the treatment of patients with relapsed and/or refractory MM (RRMM). Ixazomib is an orally bioavailable PI that preferentially binds to the $\beta 5$ subunit of the $20 \mathrm{~S}$ proteasome and inhibits the chymotrypsin-like activity. Ixazomib was approved by the US FDA in 2015; it is indicated in combination with lenalidomide and dexamethasone for the treatment of patients with RRMM. This review provides an overview of the biological effects and pivotal clinical trials of these PI-combination regimens, and discusses the future outlook with regards to the treatment of MM.

\section{Proteasome Inhibitors}

PIs have different chemical structures, and distinct pharmacokinetics and pharmacodynamics characteristics (Table 1) [6,7]. New PIs, including marizomib (NPI-0052), oprozomib (ONX0912), and delanzomib (CEP-18770), are being investigated. 
Table 1. Chemical and pharmacological features of different proteasome inhibitors.

\begin{tabular}{ccccccc}
\hline Agents & $\begin{array}{c}\text { Active } \\
\text { Moiety }\end{array}$ & $\begin{array}{c}\text { Binding } \\
\text { Kinetics }\end{array}$ & $\begin{array}{c}\text { Therapeutic } \\
\text { Targets }\end{array}$ & $\begin{array}{c}\text { IC50 } \beta 5 \\
\text { (nM) }\end{array}$ & $\begin{array}{c}\text { Half-Life } \\
\text { (min) }\end{array}$ & $\begin{array}{c}\text { Route of } \\
\text { Administration }\end{array}$ \\
\hline $\begin{array}{c}\text { Bortezomib } \\
\mathbf{( P S - 3 4 1 )}\end{array}$ & Boronate & Reversible & $\beta 5>\beta 1$ & 5.7 & 110 & IV or SC \\
$\begin{array}{c}\text { Carfilzomib } \\
\mathbf{( P R - 1 7 1 )}\end{array}$ & Epoxyketone & Irreversible & $\beta 5>\beta 2 / \beta 1$ & 5 & $<30$ & IV \\
$\begin{array}{c}\text { Ixazomib } \\
\text { (MLN9708) }\end{array}$ & Boronate & Reversible & $\beta 5>\beta 1$ & 5.9 & 18 & Oral \\
$\begin{array}{c}\text { Marizomib } \\
\text { (NPI-0052) }\end{array}$ & B-Lactone & Irreversible & $\beta 5>\beta 2>\beta 1$ & 9.1 & $10-15$ & IV or SC \\
$\begin{array}{c}\text { Oprozomib } \\
\text { (ONX0912) }\end{array}$ & Epoxyketone & Irreversible & $\beta 5$ & $6-12$ & $30-90$ & Oral \\
$\begin{array}{c}\text { Delanzomib } \\
\text { (CEP-18770) }\end{array}$ & Boronate & Reversible & $\beta 5>\beta 1$ & 5.6 & $62(\mathrm{hrs})$ & Oral \\
\hline
\end{tabular}

IV: intravenous, SC: subcutaneous, IC50: half maximal inhibitory concentration, adapted from Moreau P. et al. [6] and Teicher B.A. et al. [7].

\section{Mechanism of Action of PIs}

The ubiquitin proteasome pathway (UPP) is the essential mechanism for protein catabolism in the nucleus and cytoplasm of eukaryotic cells. The proteasome is a large multi-protein complex consisting of multicatalytic proteases and is responsible for degrading or processing intracellular proteins. The $20 \mathrm{~S}$ proteasome is created by four stacked rings which contain 28 protein subunits. Two of these rings consist of seven $\alpha$-subunits and the other two consist of seven $\beta$-subunits. Three $(\beta 1, \beta 2$, and $\beta 5$ ) of the seven $\beta$-subunits have proteasome enzymatic activities that have been characterized as chymotrypsin-like [8]. In MM cells, large amounts of monoclonal proteins are produced and secreted. By inhibiting proteasome function, misfolded or unfolded proteins are accumulated in the endoplasmic reticulum (ER), which is known as ER stress. ER stress leads to activate pro and antiproliferative signals, disrupts cell cycle regulation, activates apoptotic pathways, and ultimately, results in cell death $[9,10]$. A recent report demonstrated that co-inhibition of $\beta 1$ or $\beta 2$ with $\beta 5$ activity achieves meaningful functional proteasome inhibition and cytotoxicity in MM cells [11]. Interestingly, only high-dose carfilzomib from the PIs that are currently available has been shown to provide $\beta 2 / \beta 5$ co-inhibition and to have a more potent cytotoxic effect in MM cells. These findings raise the possibility that high-dose carfilzomib might be effective in other PI-resistant MM cells.

Besides the ER stress-related apoptosis by proteasome inhibition as described above, there are a number of molecular effects of proteasome inhibition on MM cells (Figure 1). The classical mechanism of action of bortezomib on MM cells was an inhibitory effect on the transcription factor nuclear factor- $\mathrm{kB}(\mathrm{NF}-\mathrm{kB})$ pathway activation, which is essential for myelomagenesis $[12,13]$. NF- $\mathrm{kB}$ induces several growth and angiogenesis factors including interleukin-6 (IL-6) and vascular endothelial growth factor (VEGF), cell cycle regulators including c-Myc and cyclin D1 and enhances the adherence of MM cells to stromal cells. PIs suppress NF- $k B$ activity through stabilizing the inhibitory molecule I $\kappa B$ [14]. However, a recent study has demonstrated that bortezomib promotes constitutive NF- $\kappa B$ activity in MM cells, suggesting that the effects of bortezomib on the NF-kB pathway may be different among cell types and dominant types of canonical or non-canonical NF- $\mathrm{kB}$ pathways in MM cells $[15,16]$. Other putative mechanism of cellular toxicity induced by PIs is direct induction of apoptosis via c-Jun NH2-terminal kinase (JNK) and p53 $[17,18]$. The JNK activation leads to apoptosis through the upregulation of Fas and activation of caspase- 8 and caspase-3. Accumulation and phosphorylation p53 by proteasome inhibition induces pro-apoptotic proteins including NADPH oxidase activator (NOXA) and Bcl-2-associated X protein (Bax), resulting in apoptosis via mitochondrial dysfunction, such as cytochrome-c release and membrane potential dysregulation. Bortezomib also decreases the expression of several cell adhesion molecules, such as very late antigen (VLA)-4, leading to resensitizing adhesion-mediated drug resistance of MM cells [19]. 


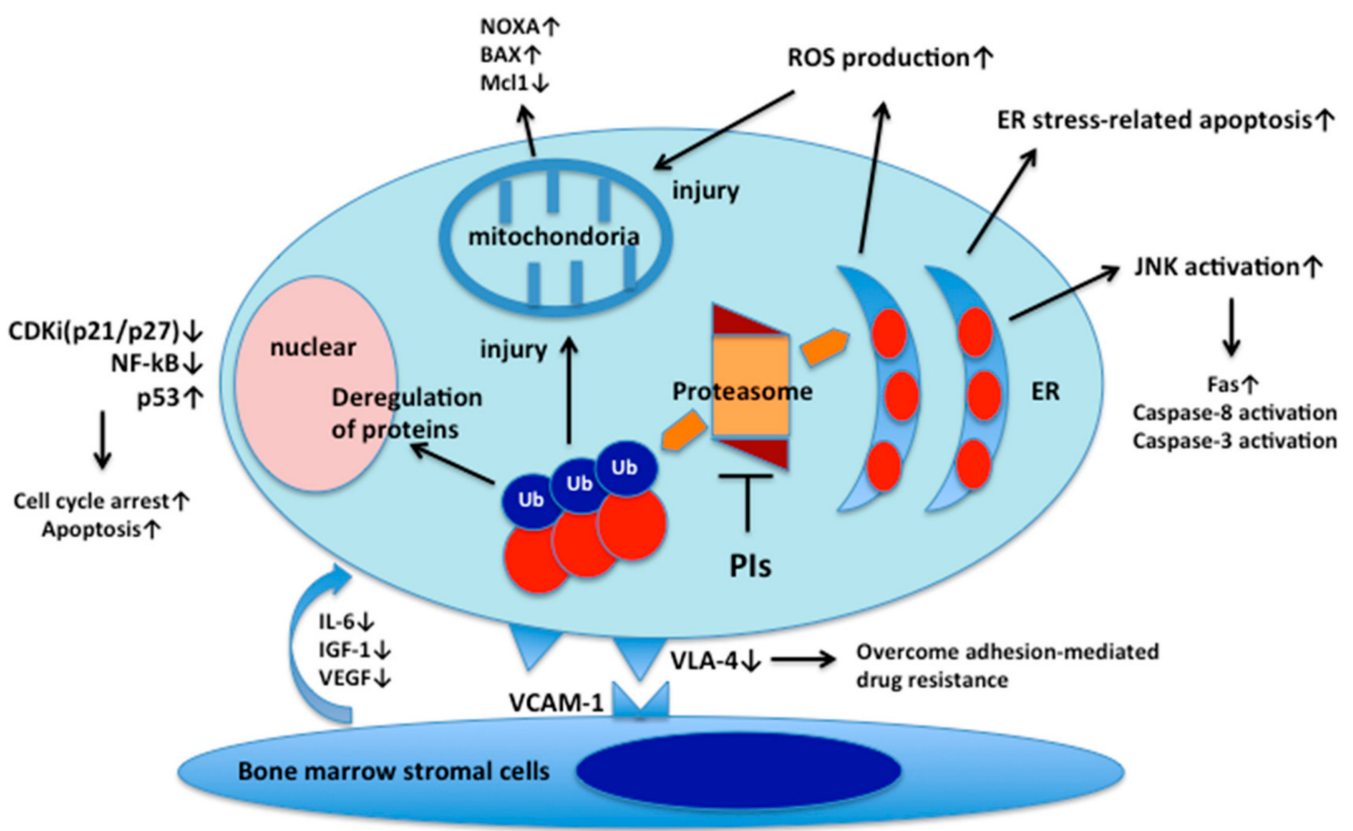

Figure 1. Molecular effects of proteasome inhibition on multiple myeloma cells.

Proteasome inhibitors (PIs) induces the accumulation of unfolded and misfolded proteins, leading to apoptosis and cell death through ER stress, reactive oxygen species production, JNK and p53 activation, cyclin-dependent kinase inhibitors, and pro-apoptotic proteins induction. Bortezomib inhibits production of cytokines such as IL-6, insulin-like growth factor-1 (IGF-1), and VEGF in bone marrow stromal cells. Bortezomib also inhibits VLA-4 expression, resulting in overcoming cell adhesion-mediated drug resistance.

\section{Bortezomib}

Bortezomib is a boronic acid dipeptide that reversibly binds to the chymotrypsin- and caspase-like active sites and inhibits these enzyme activities [6,20]. Bortezomib has been shown to directly lead to apoptosis of MM cells, inhibit the NF- $\mathrm{KB}$ activation both in cells and tumor microenvironment, and inhibit adherence of myeloma cells to bone marrow stromal cells [14,21,22].

\subsection{Bortezomib-Based Combinations for Transplant-Eligible Patients}

Selected bortezomib-containing regimens for initial therapy in transplant-eligible patients with MM are shown in Table 2.

Table 2. Selected bortezomib-containing regimens for upfront treatment of transplant-eligible MM.

\begin{tabular}{|c|c|c|c|c|c|}
\hline Trials & Phase & Patients, $n$ & ORR (CR) & $\begin{array}{c}\text { Median PFS } \\
\text { (Months) }\end{array}$ & Median OS (Months) \\
\hline $\begin{array}{l}\text { IFM2005-01 [23] } \\
\text { (VD vs. VAD) }\end{array}$ & III & 482 & $\begin{array}{c}78.5 \% \text { vs. } 62.8 \% \\
\text { ( } \geq \text { nCR: } 14.8 \% \text { vs. } \\
6.4 \%)\end{array}$ & 36.0 vs. 20.7 & 81.4 vs. 77.4 \\
\hline $\begin{array}{l}\text { DSMM-XI [24] } \\
\text { (VCD) }\end{array}$ & II & 414 & $85.4 \%(7.4 \%)$ & 35.3 & NR \\
\hline $\begin{array}{l}\text { GIMEMA [25] } \\
\text { (VTD vs. TD) }\end{array}$ & III & 480 & $\begin{array}{c}\text { 93\% vs. } 79 \% \\
\text { ( } 2 \text { nCR: } 31 \% \text { vs. } \\
11 \% \text { ) }\end{array}$ & $68 \%$ vs. $56 \%$ at $3-y r$ & $86 \%$ vs. $84 \%$ at $3-y r$ \\
\hline $\begin{array}{c}\text { GEM05-MENOS65 [26] } \\
\text { (VTD vs. TD vs. CTx + V) }\end{array}$ & III & 386 & $\begin{array}{c}85 \% \text { vs. } 64 \% \text { vs. } \\
75 \% \\
\text { ( } \geq \text { nCR: } 35 \% \text { vs. } 14 \% \\
\text { vs. } 21 \%)\end{array}$ & $\begin{array}{c}56.2 \text { vs. } 28.2 \text { vs. } \\
35.5\end{array}$ & (not reported) \\
\hline
\end{tabular}


Table 2. Cont.

\begin{tabular}{|c|c|c|c|c|c|}
\hline Trials & Phase & Patients, $n$ & ORR (CR) & $\begin{array}{l}\text { Median PFS } \\
\text { (Months) }\end{array}$ & Median OS (Months) \\
\hline $\begin{array}{l}\text { IFM2013-04 [27] } \\
\text { (VTD vs. VCD) }\end{array}$ & III & 340 & $\begin{array}{c}\text { >VGPR: } 66.3 \% \text { vs. } \\
56.2 \% \\
(13 \% \text { vs. } 8.9 \%)\end{array}$ & (not evaluated) & (not evaluated) \\
\hline $\begin{array}{c}\text { HOVON-65/GMMG-HD4 } \\
\text { [28] } \\
\text { (PAD vs. VAD) }\end{array}$ & III & 744 & $\begin{array}{c}78 \% \text { vs. } 77 \% \\
\text { ( } \geq \text { nCR: } 31 \% \text { vs. } \\
15 \%)\end{array}$ & 36 vs. 27 & $78 \%$ vs. $70 \%$ at $3-y r$ \\
\hline $\begin{array}{c}\text { IFM2009 [29] } \\
(\text { VRD } \pm \text { ASCT) }\end{array}$ & III & 700 & $\begin{array}{c}99 \% \text { vs. } 97 \% \\
(59 \% \text { vs. } 48 \%)\end{array}$ & 50 vs. 36 & $81 \%$ vs. $82 \%$ at $4-\mathrm{yr}$ \\
\hline $\begin{array}{l}\text { CASSIOPEIA [30] } \\
\text { (D-VTD vs. VTD) }\end{array}$ & III & 1085 & $\begin{array}{c}92.6 \% \text { vs. } 89.9 \% \\
\text { (sCR: } 29 \% \text { vs. } 20 \% \text { ) }\end{array}$ & NR vs. NR & (not reported) \\
\hline
\end{tabular}

VD, bortezomib + dexamethasone; VCD, bortezomib + cyclophosphamide + dexamethasone; TD, thalidomide + dexamethasone; VTD, TD + Bortezomib; CTx + V, chemothertapy + bortezomib; PAD, doxorubicin + bortezomib + dexamethasone; VAD, vincristine + doxorubicin + dexamtheasone; VRD, bortezomib + lenalidomide + dexamethasone; ASCT, autologous stem-cell transplantation; D-VTD, daratumumab + VTD; ORR, overall response rate; CR, complete response; nCR, near CR; sCR, stringent CR: VGPR, very good partial response; NR, not reached; PFS, progression-free survival; OS, overall survival.

\subsubsection{Bortezomib and Dexamethasone (BD)}

Several phase II studies evaluated bortezomib plus dexamethasone (BD) induction. The response rates were $66 \%$ to $90 \%$, including $15 \%$ to $21 \%$ with complete response (CR) and $31.5 \%$ to $70 \%$ with a very good partial response (VGPR) or better [31-33]. Based on these promising results, the intergroupe francophone du Myélome (IFM) 2005-01 phase III study was conducted; it compared BD with vincristine, doxorubicin, and dexamethasone (VAD) as induction before autologous stem cell transplantation (ASCT) in previously untreated patients [23]. The response rates after induction were significantly higher in the BD group than in the VAD group (78.5\% vs. $62.8 \%$ ). After first ASCT, CR/near CR (nCR) and VGPR or better rates remained significantly higher in the BD group than in the VAD group (CR/nCR $35 \%$ vs. $18.4 \%$, VGPR or better $54.3 \%$ vs. $37.2 \%$, respectively). There was a trend for improved progression-free survival (PFS) in the BD group versus the VAD group (36.0 vs. 20.7 months, $p=0.06$ ). However, three-year overall survival (OS) rates were not significantly different ( 81.4 vs. 77.4 months). This might be due to the influence of lenalidomide consolidation and maintenance for more than half the patients in each group. Although severe adverse events (AEs) were comparable between two groups, hematologic toxicity and treatment-related mortality were more frequently observed in the VAD group. On the other hand, grade 3 or 4 peripheral neuropathy (PN) during induction was more frequently observed in the BD group compared to the VAD group $(9.2 \%$ vs. $2.5 \%)$.

\subsubsection{Bortezomib, Cyclophosphamide, and Dexamethasone (VCD)}

Several studies have shown that a combination of bortezomib, cyclophosphamide, and dexamethasone (VCD) is an effective regimen, with favorable tolerability in relapsed and/or refractory MM [34-37]. The VCD regimen as induction therapy has also been shown to be effective, in several small studies, for patients with previously untreated MM [38-40]. The open-label, prospective, multicenter phase II, Deutsche studiengruppe multiples myeloma (DSMM) XI trial was conducted; this evaluated the efficacy and safety of VCD as induction therapy in 414 patients with newly diagnosed MM [41]. Patients received three 21-day cycles of VCD before ASCT. The overall response rate (ORR) was $85.4 \%$ and the rate of CR was $7.4 \%$. The ORR after induction was similar between patients with or without high-risk cytogenetics ( $86.2 \%$ vs. $84.3 \%$ ). At 55.5 months of a median follow-up, the median PFS and OS were 35.3 months and not reached, respectively. However, the median PFS was significantly shorter in patients with high-risk versus standard-risk cytogenetics (19.9 vs. 43.6 months, $p<0.0001)$, as well as median OS (54.7 vs. not reached, $p=0.0022)$. The most common grade 3 or higher AEs were leukopenia (31.4\%) and thrombocytopenia (6.8\%). 


\subsubsection{Bortezomib, Thalidomide, and Dexamethasone (VTD)}

Recently, the addition of a third agent to BD has been evaluated in phase II/III studies. According to the results, the efficacy of triplet regimens generally seemed better than doublet regimens. The GIMEMA Italian myeloma network reported the results of a randomized phase III study that compared bortezomib, thalidomide plus dexamethasone (VTD) with thalidomide plus dexamethasone (TD) as induction therapy before, and consolidation therapy after, double ASCT in previously untreated MM [25]. The primary endpoint, the CR or nCR rate after induction therapy was significantly higher in the VTD group versus the TD group ( $31 \%$ vs. $11 \%, p<0.0001)$. After consolidation therapy, the CR or $\mathrm{nCR}$ rate was also significantly higher in the VTD group versus the TD group ( $62 \%$ vs. $45 \%, p=0.0002)$. In ddition, the median PFS was significantly longer in the VTD group versus the TD group (Hazard ration: HR $0.63,95 \% 0.45-0.88, p=0.0061$ ). The estimated 3 -year rate of PFS was $68 \%$ in the VTD group and $56 \%$ in the TD group ( $p=0.0057$ ). The 3 -year OS was $86 \%$ in the VTD group and $84 \%$ in the TD group $(p=0.30)$. Grade 3 or 4 AEs were reported in a significantly higher number of patients on VTD $(56 \%)$ than in those on TD (33\%), with a higher incidence of PN in patients on VTD $(10 \%)$ than in those on TD (5.2\%). These results suggest that VTD induction therapy before ASCT significantly improves the rate of $\mathrm{CR}$ or $\mathrm{nCR}$ and PFS versus TD in transplant-eligible MM patients. In addition, the Spanish myeloma group reported the results of a randomized phase III trial comparing VTD versus TD versus vincristine, BCNU, melphalan, cyclophosphamide, plus prednisone, and vincristine, BCNU, doxorubicin, plus dexamethasone, and bortezomib (VBMCP/VBAD/B) in patients aged 65 years or younger with MM [26]. The primary endpoint was CR rate after induction therapy and ASCT. The CR rate was significantly higher in the VTD group than in the TD group ( $35 \%$ vs. $14 \%, p=0.001)$ or in the VBMCP/VBAD/B group ( $35 \%$ vs. $21 \%, p=0.01)$. The median PFS was significantly longer in the VTD group (56.2 vs. 28.2 vs. 35.5 months, $p=0.01$ ). The CR rate after ASCT was higher in the VTD group than in the TD group ( $46 \%$ vs. $24 \%, p=0.004)$ or in the VBMCP/VBAD/B group $(46 \%$ vs. $38 \%, p=0.1)$.

VCD has demonstrated a high response rate in prospective phase II and phase III clinical trials [24,39-41]. The IFM conducted a randomized trial of head-to-head comparison between VTD and VCD prior to ASCT in patients with untreated MM [27]. After four cycles, the rate of VGPR or better (primary endpoint) was significantly higher in the VTD group than in the VCD group (66.3\% vs. $56.2 \%, p=0.05$ ). Hematologic toxicity was higher in the VCD group, with significantly increased rates of grade 3 or 4 anemia, thrombocytopenia, and neutropenia. Overall, these results show that the combination of a PI plus IMiD plus dexamethasone is the best option prior to intensive therapy and ASCT, although both VTD and VCD are active induction regimens.

\subsubsection{Bortezomib, Doxorubicin, and Dexamethasone (PAD)}

The randomized phase III HOVON-65/GMMG-HD4 trial was conducted; this compared the efficacy and safety of VAD with bortezomib, doxorubicin plus dexamethasone (PAD) as pre-ASCT induction, followed by thalidomide and bortezomib maintenance [28]. The CR rate was significantly higher after PAD induction versus VAD ( $31 \%$ vs. $15 \%, p<0.001)$ and bortezomib maintenance versus thalidomide $(49 \%$ vs. $34 \%, p<0.001)$. After a median follow-up of 41 months, significant longer PFS was observed in the PAD group than in the VAD group (35 vs. 28 months, HR 0.75, $p=0.002$ ). Notably, OS was also superior after PAD plus bortezomib maintenance compared to VAD plus thalidomide maintenance. A benefit was also observed in patients with del(17p) (mPFS. 22 vs. 12 months, HR 0.47, $p<0.01$; median OS, not reached vs. 24 months, HR 0.36, $p=0.003)$.

\subsubsection{Bortezomib, Lenalidomide, and Dexamethasone (VRD)}

To prolong PFS and OS, one goal of frontline treatment is to maximize the depth of response. Although thalidomide and lenalidomide are both IMiDs, lenalidomide appears to be an ideal partner with bortezomib, rather than thalidomide, because the combination of bortezomib with thalidomide is limited by the occurrence of PN. A dose-escalation study demonstrated the promising efficacy and 
tolerability of bortezomib in combination with lenalidomide plus dexamethasone (VRD) as induction followed by ASCT and VRD maintenance [42]. On the basis of these studies, a randomized phase III IFM2009 trial was conducted; this evaluated the timing of ASCT in the era of triplet induction therapy with bortezomib and lenalidomide. Patients received induction therapy with three cycles of VRD and then consolidation with either five cycles of VRD or upfront ASCT followed by two additional cycles of VRD [29]. Lenalidomide as maintenance was given for one year in both groups. The median PFS was significantly longer in the upfront ASCT group than in the VRD-alone group (50 months vs. 36 months, HR $0.65, p<0.001$ ). The rate of CR was significantly higher in the ASCT group than in the VRD-alone group (59\% vs. $48 \%, p=0.03$ ). Minimal residual disease (MRD) negativity was also higher in the ASCT group than in the VRD-alone group $(79 \%$ vs. $65 \%, p<0.001)$. However, OS at 4 years did not differ significantly between both groups ( $81 \%$ vs. $82 \%$ ). These results indicated that upfront ASCT is still necessary and a standard of care in the era of VRd regimen. Recently, the phase III PETHEMA/GEM2012 study evaluated VRD for six cycles followed by ASCT conditioned with intravenous busulfan plus melphalan versus melphalan and post-transplant consolidation with two cycles of VRD [43]. The rates of CR and VGPR or better after induction therapy were $33.4 \%$ and $66.6 \%$, respectively. A stringent $\mathrm{CR}(\mathrm{sCR})$ rate was $26.2 \%$. In patients with high-risk cytogenetics, the rates of CR and VGPR or better were $34.8 \%$ and $70.7 \%$, respectively. The CR rate after ASCT and consolidation were $44.1 \%$ and $50.2 \%$. In addition, MRD negativity (median $3 \times 10^{-6}$ sensitivity) increased from induction $(28.8 \%)$ to transplant $(42.1 \%)$ and consolidation $(45.2 \%)$. The most common grade 3 or 4 hematological AEs during induction were neutropenia and thrombocytopenia $(12.9 \%$ and $9.2 \%$ ). Although grade 2 or higher PN during induction was observed in $17 \%$ of the patients, the frequency of grade 3 and $4 \mathrm{PN}$ was low $(3.7 \%$ and $0.2 \%$ ). These results indicated that VRD induction and consolidation is highly effective and well-tolerated in previously untreated MM. VRD induction regimen is being most widely used at present.

\subsubsection{Daratumumab, Bortezomib, Thalidomide, and Dexamethasone (D-VTD)}

VTD followed by ASCT is the standard treatment in Europe for transplant-eligible patients with previously untreated MM. A randomized, open-label, phase III CASSIOPEIA trial comparing CD38 monoclonal antibody, daratumumab plus VTD (D-VTD) with VTD alone was conducted [30]. Patients received four cycles of induction and two post-transplant consolidation cycles of D-VTD or VTD alone. The primary endpoint of part 1 was sCR assessed 100 days after ASCT. The rates of sCR and CR or better in the D-VTD group were $29 \%$ and $39 \%$, and those in the VTD group were $20 \%$ and $26 \%$. The MRD negativity $\left(10^{-5}\right.$ sensitivity threshold) was also higher in the D-VTD group than in the VTD group $(64 \%$ vs. $44 \%, p<0.0001)$, suggesting that addition of daratumumab to VTD leads to deeper response versus VTD alone. The median PFS was not reached in either group (HR 0.47, $p<0.0001$ ). Grade 3 or 4 neutropenia were observed in 28\% in the D-VTD group and 15\% in the VTD group, respectively. This is the first study showing that the addition of daratumumab to standard of care has the significant clinical benefit in transplant-eligible patients with previously untreated MM.

\subsection{Bortezomib-Based Combinations for Transplant-Ineligible Patients}

Melphalan plus prednisone (MP) has historically been the most widely accepted treatment and considered as one of the standards of care in transplant-ineligible myeloma patients. Since novel agents have been developed, the treatment choices for newly diagnosed myeloma patients have dramatically changed. Selected bortezomib-containing regimens for initial therapy in transplant-ineligible patients with MM are shown in Table 3. 
Table 3. Selected bortezomib-containing regimens for upfront treatment of transplant-ineligible MM.

\begin{tabular}{|c|c|c|c|c|c|}
\hline Trials & Phase & Patients, $n$ & ORR (CR) & $\begin{array}{l}\text { Median PFS } \\
\text { (Months) }\end{array}$ & $\begin{array}{c}\text { Median OS } \\
\text { (Months) }\end{array}$ \\
\hline $\begin{array}{c}\text { VISTA [44] } \\
\text { (VMP vs. MP) }\end{array}$ & III & 682 & $\begin{array}{l}71 \% \text { vs. } 35 \% \\
\text { (30\% vs. } 4 \%)\end{array}$ & $\begin{array}{c}\text { TTP } 24.0 \text { vs. } \\
16.6\end{array}$ & 56.4 vs. 43.1 \\
\hline $\begin{array}{c}\text { ALCYONE [45] } \\
\text { (D-VMP vs. VMP) }\end{array}$ & III & 706 & $\begin{array}{c}90.9 \% \text { vs. } 73.9 \% \\
(42.6 \% \text { vs. } \\
24.4 \%)\end{array}$ & 36.4 vs. 18.1 & NR vs. NR \\
\hline $\begin{array}{l}\text { SWOG-S0777 [46] } \\
\text { (VRd vs. Rd) }\end{array}$ & III & 525 & $\begin{array}{l}82 \% \text { vs. } 72 \% \\
(16 \% \text { vs. } 8 \%)\end{array}$ & 43 vs. 30 & 75 vs. 64 \\
\hline VRd Lite [47] & II & 50 & $\begin{array}{c}86 \% \\
(\geq \text { VGPR } 66 \%)\end{array}$ & 35.1 & NR \\
\hline
\end{tabular}

MP, melphalan + prednisone; VMP, bortezomib + MP; D-VMP, daratumumab + VMP; Rd, lenalidomide + dexamethasone; VRD, bortezomib + Rd; ORR, overall response rate; $C R$, complete response; VGPR, very good partial response; PFS, progression-free survival; TTP, time to progression; OS, overall survival; NR, not reached.

\subsubsection{Bortezomib, Melphalan, and Prednisone (VMP)}

Bortezomib has a synergistic activity in vitro in combination with melphalan [48]. In the phase I or II studies of VMP, ORR and CR rate were $89 \%$ and $32 \%$, respectively. Median time to progression (TTP) was 27 months and OS was 38 months [49,50]. Based on these promising results, the VISTA study was conducted; it compared VMP with MP for patients with previously untreated MM [44]. The primary endpoint, TTP in the VMP group, and in the control group was 24.0 and 16.6 months, respectively (hazard ratio $(\mathrm{HR})=0.48 ; p<0.001$ ). The ORR was also higher in the VMP group than in the control group $(71 \%$ vs. $35 \% ; p<0.001)$, and the CR rates was also higher in the VMP group than in the control group $(30 \%$ and $4 \%, p<0.001)$. Notably, VMP was superior to MP in terms of OS (HR 0.61). An updated follow-up study confirmed a survival advantage for VMP [51]. Median OS was not reached in the VMP group and 43 months in the MP group, respectively. VMP regimen is now considered as one of the standards of care in transplant-ineligible patients with previously untreated MM.

\subsubsection{Daratumumab Plus VMP (D-VMP)}

Daratumumab has a variety of mechanisms of action, including direct antitumor effect [52-58]. The ALCYONE trial has demonstrated the superiority of D-VMP versus VMP in terms of PFS. The 18-month PFS rate was $71.6 \%$ in the D-VMP group versus $50.2 \%$ in the control group (HR 0.50 , $p<0.001)$ [45]. The ORR was significantly higher in the D-VMP group than in the VMP group $(90.9 \%$ and $73.9 \%, p<0.001$ ). The rate of CR or better (including SCR) was also higher in the D-VMP group than in the control group $(42.6 \%$ and $24.4 \%, p<0.001)$. Notably, MRD negativity $\left(10^{-5}\right.$ sensitivity threshold) was higher in the D-VMP group than in the control group $(22.3 \%$ and $6.2 \%, p<0.001)$. Although the most common AEs of grade 3 or 4 were hematologic, the frequencies of neutropenia, thrombocytopenia, and anemia were comparable between both groups; neutropenia was observed in $39.9 \%$ in the D-VMP group and in $38.7 \%$ in the VMP group, thrombocytopenia in $34.4 \%$ and $37.6 \%$, and anemia in $15.9 \%$ and $19.8 \%$, respectively. The rate of grade 3 or 4 infections was higher in the D-VMP group than in the control group (23.1\% and $14.7 \%)$. However, the treatment discontinuation rate due to infections was low $(0.9 \%$ and $1.4 \%)$. Daratumumab-associated infusion-related reactions were observed in $27.7 \%$ of the patients. Thus, the addition of daratumumab on VMP did not increase overall toxicity except for infection. Daratumumab plus VMP is a new standard of care for patients with previously untreated MM who are ineligible for ASCT.

\subsubsection{Bortezomib, Lenalidomide, and Dexamethasone (VRd)}

Lenalidomide and bortezomib have different, but synergistic, mechanisms of action [59]. Recently, the southwest oncology group (SWOG) study S0777 was reported; it compared VRd with Rd in newly 
diagnosed MM without intention for immediate ASCT [46]. After a median follow-up of 55 months, the median PFS was longer in the VRd group compared with the Rd group (43 months vs. 30 months, HR $0.712, p=0.0037)$. The median OS was also longer in the VRd group compared with the Rd group (75 vs. 64 months; HR $0.709, p=0.025$ ). The rates of overall response were $82 \%$ in the VRd group and $72 \%$ in the Rd group. In addition, the rates of CR were $16 \%$ and $8 \%$, respectively. Adverse events of grade 3 or higher were observed in $82 \%$ in the VRd group and $75 \%$ in the Rd group. The discontinuation rates due to AEs were $23 \%$ in the VRd group and $10 \%$ in the Rd group, respectively.

For elderly patients, the dosing schedule of VRd may be more challenging. Reduced dose and schedule of drugs may be more tolerable and maintain efficacy. Recently, a phase II study of modified VRd (VRd lite) was reported [47]. Fifty-three eligible patients were enrolled and 50 received at least one dose of therapy. The ORR and VGPR or better were obtained in $86 \%$ and $66 \%$ of patients, respectively. Median PFS was 35.1 months and the median OS was not reached at a median follow-up of 30 months. Notably, PN was observed in 31 (62\%) patients with only one patient experiencing grade 3 symptoms. Overall, VRd lite seems likely to be a well-tolerated and highly effective regimen in transplant-ineligible MM patients and may represent the new standard of care.

\section{Carfilzomib}

Carfilzomib binds irreversibly to the $\beta 5$ subunit of the constitutive proteasome and inhibits the chymotrypsin-like activity. The safety profile of this agent is quite different from other PIs. In particular, the agent is associated with cardiovascular AEs. Recently, Efentakis et al. demonstrated that cardiotoxicity by carfilzomib is associated with the autophagy pathway and upregulation of protein phosphatase (PP)-2A phosphatase activity but not the inhibition of the proteasome function [60]. Selected carfilzomib-containing regimens for relapsed and/or refractory MM patients are shown in Table 4.

Table 4. Selected carfilzomib or ixazomib-containing regimens for relapsed and/or refractory MM.

\begin{tabular}{|c|c|c|c|c|c|}
\hline Trials & Phase & Patients, $n$ & ORR (CR) & $\begin{array}{l}\text { Median PFS } \\
\text { (Months) }\end{array}$ & $\begin{array}{l}\text { Median OS } \\
\text { (Months) }\end{array}$ \\
\hline $\begin{array}{l}\text { ENDEAVOR [61] } \\
\text { (Kd vs. Vd) }\end{array}$ & III & 929 & $77 \%$ vs. $63 \%$ & 18.7 vs. 9.4 & 47.6 vs. 40.0 \\
\hline $\begin{array}{l}\text { A.R.R.O.W. [62] } \\
\text { (weekly Kd vs. } \\
\text { twice-weekly Kd) }\end{array}$ & III & 478 & $\begin{array}{l}62.9 \% \text { vs. } 40.8 \% \\
(7.1 \% \text { vs. } 1.7 \%)\end{array}$ & 11.2 vs. 7.6 & (not reported) \\
\hline $\begin{array}{l}\text { ASPIRE [63] } \\
\text { (KRd vs. Rd) }\end{array}$ & III & 525 & $\begin{array}{l}82 \% \text { vs. } 72 \% \\
(16 \% \text { vs. } 8 \%)\end{array}$ & 26.3 vs. 17.6 & 48.3 vs. 40.4 \\
\hline DKd [64] & $\mathrm{Ib}$ & 85 & $84 \%(33 \%)$ & $\begin{array}{c}\text { NR } \\
(74 \% \text { and } 66 \% \\
\text { at } 12 \text {-and } 18- \\
\text { months) }\end{array}$ & $\begin{array}{l}\text { NR (82\% at } \\
12 \text {-months) }\end{array}$ \\
\hline $\begin{array}{l}\text { TOURMALINE-MM1 } \\
\text { [65] (IRd vs. Rd) }\end{array}$ & III & 722 & $\begin{array}{l}78 \% \text { vs. } 72 \% \\
(12 \% \text { vs. } 7 \%)\end{array}$ & 20.6 vs. 14.7 & NR vs. NR \\
\hline
\end{tabular}

Kd, carfilzomib + dexamethasone; Vd, bortezomib + dexamethasone; Rd, lenalidomide + dexamethasone; KRD, carfilzomib + Rd; DKd, daratumumab + Kd; IRd, ixazomib + Rd; ORR, overall response rate; CR, complete response; PFS, progression-free survival; OS, overall survival; NR, not reached.

\subsection{Carfilzomib-Based Therapy in Relapsed and/or Refractory MM}

\subsubsection{Carfilzomib and Dexamethasone (Kd)}

A phase I study was conducted to evaluate the maximum-tolerated dose (MTD), pharmokinetics, and pharmacodynamics of carfilzomib administered as a 30-minute intravenous infusion [66]. Single-agent carfilzomib on days 1, 2, 8, 9, 15, and 16 of a 28-day cycle was given in thirty-three relapsed and refractory MM patients. The carfilzomib doses of days 1 and 2 on cycle 1 were $20 \mathrm{mg} / \mathrm{m}^{2}$, followed thereafter with doses escalated to $36,45,56$, or $70 \mathrm{mg} / \mathrm{m}^{2}$. In addition, carfilzomib was combined 
with low-dose dexamethasone (40 mg/week). Dose-limiting toxicities were reported in two patients at $70 \mathrm{mg} / \mathrm{m}^{2}$, who had renal tubular necrosis and proteinuria. The MTD was established at $56 \mathrm{mg} / \mathrm{m}^{2}$. ORR was $50 \%$ in the $56 \mathrm{mg} / \mathrm{m}^{2}$ cohort.

In 2014, a single-arm/single-center phase II study of carfilzomib with or without low-dose dexamethasone in relapsed MM was published [67]. After two cycles of single-agent carfilzomib, $20 \mathrm{mg}$ of dexamethasone could be added if the response was less than PR or if there was progressive disease. Forty-four patients were enrolled; all of these had had prior bortezomib and IMiDs and a median of five prior regimens. The ORR was 55\% in 42 evaluable patients. Median duration of response (DOR), PFS, and OS were 11.7, 4.1, and 20.3 months, respectively. The most frequent grade 3 or 4 AEs were lymphopenia (43\%), thrombocytopenia (32\%), hypertension $(25 \%)$, pneumonia $(18 \%)$, and heart failure (11\%). The discontinuation rate due to AEs was $16 \%$.

Based on these promising results, the phase III ENDEAVOR trial comparing Kd with BD in 929 patients with RRMM was initiated [61]. The carfilzomib doses of days 1 and 2 on cycle 1 were $20 \mathrm{mg} / \mathrm{m}^{2}$, followed thereafter with doses escalated to $56 \mathrm{mg} / \mathrm{m}^{2}$. Bortezomib was administered twice-weekly subcutaneously or intravenously. Median PFS was significantly improved with the Kd group versus the BD group (18.7 vs. 9.4 months; HR 0.53, $p<0.0001$ ). The ORR was higher in the Kd group than in the BD group (77\% vs. $63 \%, p<0.0001)$. The median time to response was 1.1 months in both groups. An updated analysis demonstrated that OS was also significantly improved with the carfilzomib group versus the bortezomib group (47.6 vs. 40.0 months, $p=0.010$ ). Serious AEs were reported in $48 \%$ in the carfilzomib group and in $36 \%$ in the bortezomib group. The most frequent grade 3 or higher AEs were anemia (14\% in the carfilzomib group vs. $10 \%$ in the bortezomib group), hypertension ( $9 \%$ vs. 3\%), thrombocytopenia ( $8 \%$ vs. $9 \%$ ), and pneumonia (7\% vs. $8 \%$ ). Grade 2 or higher PN was lower in the Kd group than in the BD group (6\% vs. $32 \%)$.

Carfilzomib is currently approved with a twice-weekly schedule at a dose of $27 \mathrm{mg} / \mathrm{m}^{2}$ when administered in combination with lenalidomide and dexamethasone (KRd), or at $56 \mathrm{mg} / \mathrm{m}^{2}$ when given in combination with dexamethasone $(\mathrm{Kd})$. The current twice-weekly schedule may prove burdensome for patients, especially if they are elderly and have limited access to hospital facilities. To improve the convenience of the carfilzomib schedule, preliminary studies tested higher doses of carfilzomib given in a once-weekly schedule. In the phase I/II CHAMPION-1 evaluating once-weekly carfilzomib dosing, the MTD was established as $70 \mathrm{mg} / \mathrm{m}^{2}$ in combination with dexamethasone [68]. Based on these results, the phase III study (A.R.R.O.W.) comparing the PFS of once-weekly carfilzomib with twice-weekly carfilzomib in patients with RRMM was conducted [62]. The once-weekly group received carfilzomib at $20 \mathrm{mg} / \mathrm{m}^{2}$ on day 1 during cycle 1 , and then at $70 \mathrm{mg} / \mathrm{m}^{2}$ on days 8 and 15 of all cycles thereafter. The twice-weekly group received carfilzomib at $20 \mathrm{mg} / \mathrm{m}^{2}$ on days 1 and 2 during cycle 1 , and then $27 \mathrm{mg} / \mathrm{m}^{2}$ thereafter. All patients received dexamethasone at a dose of $40 \mathrm{mg}$ on days 1,8, and 15 during all cycles and day 22 during cycles 1-9. The median PFS was significantly longer in the once-weekly group than in the twice-weekly group (11.2 months vs. 7.6 months, HR 0.69, $p=0.0029$ ). The grade 3 or higher AEs was observed in $68 \%$ of patients in the once-weekly group and in $62 \%$ of them in the twice-weekly group. The incidence of anemia and thrombocytopenia were quite similar between both groups (18\% and 7\%, respectively). Pneumonia was observed in 10\% of patients in the once-weekly group and in $7 \%$ of them on the twice-weekly group. Notably, the incidence of grade 3 or higher cardiac failure was similar between the once-weekly group and the twice-weekly group ( $4 \%$ vs. $3 \%$ ). Based on these results, US FDA approved once-weekly carfilzomib in combination with dexamethasone for RRMM in 2018.

\subsubsection{Carfilzomib, Lenalidomide, and Dexamethasone (KRd)}

Phase I and II studies showed the activity and tolerability of carfilzomib, lenalidomide, and dexamethasone (KRd) in relapsed myeloma patients. The PX-171-006 study assessed safety and tolerability of KRd regimen in 40 patients [69]. Carfilzomib was administered twice-weekly at doses of $15 \mathrm{mg} / \mathrm{m}^{2}$ to $27 \mathrm{mg} / \mathrm{m}^{2}$. Lenalidomide was administered in the first 21 days of a 28-day cycle, 
ranging from $10 \mathrm{mg}$ a day to $25 \mathrm{mg}$ a day. Dexamethasone was administered at a dose of $40 \mathrm{mg}$ weekly. The MTD was not reached. Grade 3 or higher neutropenia was observed in $42.5 \%$ of the patients, anemia in $20 \%$, thrombocytopenia in $32.5 \%$, and lymphopenia in $27.5 \%$, respectively. Grade 3 or higher fatigue was observed in $7.5 \%$ of the patients, diarrhea in $5.0 \%$, and hyperglycemia in $22.5 \%$, respectively. The ORR was $62.5 \%$ and the median DOR was 11.8 months for patients who achieved at least a PR. Median PFS was 10.2 months. The phase II dose-expansion study evaluating safety and efficacy was conducted in 52 patients treated at the maximum planned dose [70]. The ORR was 76.9\% and median DOR of 22.1 months. Median PFS was 15.4 months and median time to response was 0.95 months. In bortezomib-refractory patients, the ORR was $69.2 \%$ and the median PFS was 15.4 months. In lenalidomide-refractory patients, the ORR was $69.9 \%$ and the median PFS was relatively short (7.9 months). Grade 3 or higher neutropenia was observed in $32.7 \%$ of the patients, anemia in $19.2 \%$, thrombocytopenia in $19.2 \%$, and lymphopenia in $48.1 \%$, respectively. Fatigue and diarrhea were commonly observed (69.2\% and 57.7\%). Only one patient experienced grade 3 neuropathy. Cardiac AE of any grade was observed in $19.2 \%$ of patients, with three patients of grade 3 or higher.

Based on these findings, an ASPIRE trial comparing KRd with Rd in patients with relapsed MM was initiated [63]. The ASPIRE trial showed that the KRd group is superior in terms of PFS compared to the Rd group (26.3 vs. 17.6 months; HR 0.69, $p=0.0001$ ). The ORR was $87.1 \%$ and $66.7 \%$ in the KRd and the Rd group, respectively $(p<0.001)$. The rate of a CR or better was $31.8 \%$ and $9.3 \%$, and stringent CR rate was $14.1 \%$ and $4.3 \%$. Adverse events of grade 3 or higher were reported in $83.7 \%$ and $80.7 \%$ of patients in the KRd and the Rd groups, respectively. The treatment discontinuation rate due to AE was similar between both groups (15.3\% in the KRd and $17.7 \%$ in the Rd group). Recent report showed OS data from the ASPIRE trial. Median OS was 48.3 months for the KRd versus 40.4 months for the Rd group (HR 0.79, $p=0.0045$ ). Selected grade 3 or higher AEs of interest included acute renal failure ( $3.8 \%$ in the KRd vs. $3.3 \%$ in the Rd group, respectively), cardiac failure ( $4.3 \% \mathrm{vs.} 2.1 \%$ ), ischemic heart failure (3.8\% vs. $2.3 \%)$, and hypertension (6.4\% vs. $2.3 \%)$. Overall, the KRd regimen is considered as one of the standards of care in patients with relapsed and refractory MM.

\subsubsection{Daratumumab, Carfilzomib, and Dexamethasone (DKd)}

The number of patients treated with lenalidomide-based regimens as a front-line treatment has been recently increasing. As a result, the effective regimens for lenalidomide-refractory patients are needed. A phase $\mathrm{Ib}$ study evaluating daratumumab plus carfilzomib and dexamethasone (DKd) in patients with relapsed or refractory MM was reported [64]. In this study, eighty-five patients who did not receive carfilzomib and daratumumab were enrolled. Carfilzomib $\left(20 \mathrm{mg} / \mathrm{m}^{2}\right.$ on day 1 and thereafter $70 \mathrm{mg} / \mathrm{m}^{2}$ ) was given on days 1,8 , and 15 of each 28 -day cycle. Dexamethasone was given at $40 \mathrm{mg}$ once a week. Daratumumab was given as a single first dose of $16 \mathrm{mg} / \mathrm{kg}$ for ten patients or as a split first dose of $8 \mathrm{mg} / \mathrm{kg}$ on days 1 and 2 of cycle 2 for seventy-five patients. The ORR was $84 \%$ in the overall population compared with $79 \%$ in the lenalidomide-refractory population. The median PFS was not reached in the overall population compared with 25.7 months in the lenalidomide-refractory population. According to the cytogenetic risk group, the median PFS was not reached in the standard-risk group compared with 23 months in the high-risk group. Grade 3 or higher thrombocytopenia was observed in $31 \%$ of the patients, lymphopenia in $24 \%$, anemia in $21 \%$, and neutropenia in $21 \%$, respectively. Infusion-related reactions were observed in $60 \%$ and $43 \%$ of single and split first-dose patients, respectively. These results suggested that DKd appears to be a well-tolerated and effective regimen in patients with relapsed or refractory $\mathrm{MM}$, including refractory to lenalidomide. A randomized, open-label phase III study of DKd compared to Kd is ongoing.

\section{Ixazomib}

Ixazomib is an oral, selective and reversible PI, which inhibits the chymotrypsin-like activity of the $\beta 5$ subunit of the $20 \mathrm{~S}$ proteasome. Chemically, it is an $\mathrm{N}$-capped dipeptidyl leucine boronic acid, which is rapidly hydrolyzed in water and converted into ixazomib. The proteasome dissociation half-life 
is shorter than bortezomib. Ixazomib treatment of MM cells induced caspase-mediated apoptosis, accompanied by induction of the unfolded protein response. In vitro synergy between ixazomib and lenalidomide was detected in two of four MM cell lines evaluated in viability assays, and two MM cell lines evaluated showed the additive effect of the combination [71].

\subsection{Ixazomib-Based Therapy in Relapsed and/or Refractory $M M$}

Ixazomib, Lenalidomide, and Dexamethasone (IRd)

A phase III, prospective and randomized, double-blind TOURMALINE-MM1 study of ixazomib plus lenalidomide and dexamethasone (IRd) versus placebo plus lenalidomide and dexamethasone (placebo-Rd) in refractory and/or relapsed MM previously treated with one to three lines was reported (Table 4) [65]. Ixazomib $4 \mathrm{mg}$ was to be administered on days 1, 8, and 15 in combination with lenalidomide $25 \mathrm{mg}$ on days 1-21 and dexamethasone $40 \mathrm{mg}$ on days $1,8,15$, and 22 in a 28-day cycle until progressive disease or unacceptable toxicity. The median PFS was 20.6 months in the IRd group compared with 14.7 months in the placebo-Rd group (HR 0.74, $p=0.01$ ). Notably, IRd could overcome the negative impact of high-risk cytogenetics on PFS. The median PFS was 21.4 months in the high-risk group vs. 20.6 months in the standard-risk group. The ORR was significantly higher in the IRd group vs. in the placebo-Rd group $(78.3 \%$ vs. $72 \%, p=0.04)$, as well as the rates of CR plus very good PR ( $48 \%$ vs. $39 \%$ ). At a median follow-up of 23 months, the median OS was not reached in either study group. The most frequently AEs were diarrhea ( $42 \%$ in the IRd group vs. $36 \%$ in the Rd group), constipation ( 34 vs. $25 \%$ ), thrombocytopenia ( $28 \%$ vs. $14 \%$ ), PN ( $25 \%$ vs. $18 \%)$, vomiting ( $22 \%$ vs. $11 \%$ ) and back pain $(21 \%$ vs. $16 \%)$. Rash was observed more frequently in the IRd group compared to the placebo-Rd group ( $36 \%$ vs. $23 \%$ ). Thus, IRd regimen is one of the standards of care for patients with RRMM.

\subsection{Ixazomib Maintenance Therapy}

Recent studies have demonstrated that lenalidomide-maintenance therapy after ASCT could improve PFS and OS [72-75]. A meta-analysis showed that the discontinuation rate due to AEs was $29 \%$ in the lenalidomide maintenance group and $12 \%$ of the placebo or observation group [76]. On the other hand, bortezomib-maintenance therapy has also shown promising activity in ASCT setting $[28,77,78]$. However, there has been no phase III study demonstrating a survival benefit of PI-based maintenance therapy compared with placebo. In addition, the clinical utility of bortezomib as a maintenance treatment may be limited due to the need for parenteral administration and toxicity such as PN. Therefore, oral PI maintenance therapy including ixazomib suitable for long-term use without cumulative toxicity is needed [79].

Ixazomib Maintenance Following Autologous Stem Cell Transplantation

The phase III, double-blind, placebo-controlled TOURMALINE-MM3 study of ixazomib maintenance versus placebo in patients who underwent ASCT was conducted [80]. The study included 656 patients who achieved a PR to induction therapy followed by single ASCT. Patients were randomly assigned 3:2 to ixazomib or placebo group. Each agent was administered on days 1, 8, and 15 of each 28-day cycle. Ixazomib was administered at a dose of $3 \mathrm{mg}$ during the first four cycles and was escalated to $4 \mathrm{mg}$ after the fifth cycle if tolerated. With a median follow-up of 31 months, the median PFS (primary endpoint) was superior in the ixazomib group vs. the placebo group ( 26.5 months vs. 21.3 months, HR $0.72, p=0.0023$ ). In the subgroup analysis, PFS benefit of ixazomib maintenance was observed in patients who were aged 60 years or older, who had ISS disease stage III, and who had high-risk cytogenetics. In addition, depth of response improved during maintenance therapy in $46 \%$ of the patients in the ixazomib group and $32 \%$ of them in the placebo group. Serious AEs were observed in $27 \%$ of patients in the ixazomib group and $20 \%$ of those in the placebo group. The most common grade 3 or higher AEs were infections (15\% in the ixazomib group vs. $8 \%$ in the placebo group), gastrointestinal disease ( $6 \%$ vs. $1 \%)$, neutropenia ( $5 \%$ vs. $3 \%$ ) and thrombocytopenia ( $5 \%$ vs. 
$<1 \%$ ). The PN occurred in $19 \%$ of the patients in the ixazomib group versus $15 \%$ of them in the placebo group. Second malignancy was observed in 3\% each. The ixazomib maintenance may become a new option in the ASCT setting, especially for patients who have high-risk features or are not tolerable for lenalidomide. However, a longer follow-up is needed to evaluate OS benefit.

\section{Novel Inhibitors of Deubiqutinating Enzymes}

Novel inhibitors targeting deubiquitinating enzymes (DUBs) or ubiquitin receptors upstream of $20 S$ proteasome is under investigation. These agents may overcome PI-resistance. DUBs are antagonists of E3 ubiquitin ligases. These recognize ubiquitinated proteins and remove their ubiquitin tags by the protease activity [81]. Schwickart et al. demonstrated that DUB ubiquitin-specific-processing protease (Usp) 9x is highly expressed in MM cells and is involved in anti-apoptotic protein, Mcl-1 stabilization [82]. WP1130, a selective Usp9x inhibitor, leads to apoptosis and reduction of Mcl-1 expression in MM cells. Usp9x depletion induced upregulation of Usp24 which has shown to be involved in myeloma cell survival. Both Usp9x and 24 were expressed and activated in primary MM cells. EOAI3402153 is a novel inhibitor, which inhibits both Usps, and suppresses to cell survival and tumor growth in vivo [83]. In addition, a selective Usp7 inhibitor P5091 is being investigated in the preclinical study [84]. Higher expression of Usp7 has shown to be correlated with poor outcome in MM. On the other hand, novel inhibitors of 195 regulatory particle (RP) proteasome are also under investigation. Capzimin (CZM) inhibits the DUB Rpn11 of the 19S RP [85]. Before the entry and degradation of substrates in the $20 \mathrm{~S}$ proteasome, the polyubiquitin chains of substrates need to be removed. Rpn11 is one of the subunits of lid of the 19S RP and removes the polyubiquitin chains. CZM has been shown to be active in several cancer cell lines, including bortezomib-resistant cells. At present, other two Rpn11 inihibitors, O-phenanthroline and thilutin, are also being investigated [86,87]. The further clinical studies of these inhibitors are awaited.

\section{Future Perspectives}

Triplet regimens for MM consisting of a PI, an IMiD or an alkylator, and dexamethasone have been evaluated and widely used in the clinical setting, as described above. To improve the survival of $\mathrm{MM}$, achieving and maintaining a deeper response is important in patients who are both eligible and ineligible for transplantation. It appears that the quadruplet combination with novel agents is necessary to obtain the deeper response. The addition of monoclonal antibodies or alkylators to the traditional triplet induction regimens may be reasonable because of fewer additional side effects. However, the efficacy and safety of quadruplet regimens has, to date, not been fully elucidated. Thus, many clinical trials are ongoing. As described above, the results from part 1 of the CASSIOPEIA trial show the clinical benefit of the addition of daratumumab to VTD in transplant-eligible patients with newly diagnosed MM [30]. The phase III Myeloma XI trial randomized 1,056 transplant-eligible patients with newly diagnosed MM to either carfilzomib, cyclophosphamide, lenalidomide and dexamethasone (KCRD), cyclophosphamide, thalidomide and dexamethasone (CTD)/cyclophosphamide, lenalidomide, and dexamethasone (CRD) as an induction therapy before ASCT. Treatment with quadruplet regimen was associated with a significantly longer PFS than triplet therapy (HR 0.63, $p<0.001$ ). The 3-year PFS rate was also significantly higher in the KCRD group than in the triplet group $(64.5 \%$ vs. $50.3 \%, p<0.0001)$. No additional toxicity was observed in the quadruplet regimen [88]. The randomized, open-label, phase II GRIFFIN study investigated the use of daratumumab in combination with VRd (D-VRd) in patients with newly diagnosed MM who were eligible for transplantation. This was compared to VRD-alone. The rate of sCR (primary endpoint) was significantly higher in the D-VRd group than in the VRd group ( $42 \%$ vs. $32 \%)$. In the D-VRd group, $59 \%$ of the patients were negative for MRD $\left(10^{-5}\right.$ sensitivity threshold), as compared with $24 \%$ of those in the VRd group. The safety profile of the D-VRd quadruplet was similar to that reported for the drugs when used separately [89]. These results indicate that the addition of daratumumab to traditional triplet induction regimens could improve efficacy. 
In transplant-ineligible patients, the quadruplet regimen has just been established [45]. As described above, D-VMP is effective and tolerable for this population.

In the clinical setting, lenalidomide maintenance or continuous therapy has been performed in both transplant-eligible and -ineligible patients with MM. Maintenance approaches incorporating PIs might favor a combination approach, especially in high-risk patients. A randomized phase II study comparing ixazomib alone with ixazomib plus lenalidomide as maintenance therapy is ongoing (NCT03733691). In addition, a randomized phase III study evaluating the impact on PFS when adding ixazomib to post-transplant maintenance therapy with lenalidomide and dexamethasone after ASCT in patients with newly diagnosed MM is also ongoing (NCT02406144). The phase II trial evaluating the efficacy and safety of bortezomib in combination with lenalidomide as maintenance therapy in high-risk patients with newly diagnosed MM who received VRd regimen as induction therapy is also ongoing (NCT03641456). These results will contribute to better understanding and decision making of the optimal maintenance therapy in MM.

\section{Conclusions}

PIs are an indispensable agent for increasing PFS and quality of life, and are achieving a deeper response, especially in subgroups of patients with poor prognosis. A number of clinical studies evaluating the safety and efficacy of new combination regimens involving PIs and the other novel agents are ongoing.

Funding: This research received no external funding.

Conflicts of Interest: S.I. received honorarium from Celgene, Bristol-Myers Squibb, Takeda, Ono, and Janssen.

\section{References}

1. Palumbo, A.; Anderson, K. Multiple myeloma. N. Engl. J. Med. 2011, 364, 1046-1060. [CrossRef] [PubMed]

2. Anderson, K.C. The 39th David A. Karnofsky lecture: Bench-to-bedside translation of targeted therapies in multiple myeloma. J. Clin. Oncol. 2012, 30, 445-452. [CrossRef] [PubMed]

3. Kumar, S.K.; Dispenzieri, A.; Lacy, M.Q.; Gertz, M.A.; Buadi, F.K.; Pandey, S.; Kapoor, P.; Dingli, D.; Hayman, S.R.; Leung, N.; et al. Continuous improvement in survival in multiple myeloma: Changes in elderly mortality and outcomes in older patients. Leukemia 2014, 28, 1122-1128. [CrossRef] [PubMed]

4. Richardson, P.G.; Sonneveld, P.; Schuster, M.W.; Irwin, D.; Stadtmauer, E.A.; Facon, T.; Harousseau, J.L.; Ben-Yehuda, D.; Lonial, S.; Goldschmidt, H.; et al. A randomized comparison of bortezomib with high-dose dexamethasone in relapsed multiple myeloma. N. Engl. J. Med. 2005, 352, 2487-2498. [CrossRef]

5. Herndon, T.M.; Deisseroth, A.; Kaminskas, E.; Kane, R.C.; Koti, K.M.; Rothmann, M.D.; Habtemariam, B.; Bullock, J.; Bray, J.D.; Hawes, J.; et al. US Food and Drug Administration approval: Carfilzomib for the treatment of multiple myeloma. Clin. Cancer. Res. 2013, 19, 4559-4563. [CrossRef]

6. Moreau, P.; Richardson, P.G.; Cavo, M.; Orlowski, R.Z.; Miguel, J.F.S.; Palumbo, A.; Harousseau, J.-L. Proteasome inhibitors in multiple myeloma: 10 years later. Blood 2012, 120, 947-959. [CrossRef]

7. Teicher, B.A.; Tomaszewski, J.E. Proteasome inhibitors. Biochem. Pharmacol. 2015, 96, 1-9. [CrossRef]

8. Groen, K.; Van De Donk, N.W.C.J.; Stege, C.; Zweegman, S.; Nijhof, I. Carfilzomib for relapsed and refractory multiple myeloma. Cancer Manag. Res. 2019, 11, 2663-2675. [CrossRef]

9. Adams, J. The proteasome: A suitable antineoplastic target. Nat. Rev. Cancer 2004, 4, 349-360. [CrossRef]

10. Niewerth, D.; Jansen, G.; Assaraf, Y.G.; Zweegman, S.; Kaspers, G.J.L.; Cloos, J. Molecular basis of resistance to proteasome inhibitors in hematological malignancies. Drug Resist. Updat. 2015, 18, 18-35. [CrossRef]

11. Besse, A.; Besse, L.; Kraus, M.; Mendez-Lopez, M.; Bader, J.; Xin, B.T.; Bruin, G.D.; Maurits, E.; Overkleeft, H.S.; Driessen, C. Proteasome inhibition in multiple myeloma: Head-to head comparison of currently available proteasome inhibitors. Cell Chem. Biol. 2019, 26, 340-351. [CrossRef] [PubMed]

12. Chauhan, D.; Hideshima, T.; Mitsiades, C.; Richardson, P.; Anderson, K.C. Proteasome inhibitor therapy in multiple myeloma. Mol. Cancer Ther. 2005, 4, 686-692. [CrossRef] [PubMed]

13. Li, Z.W.; Chen, H.; Campbell, B.A.; Bonavida, B.; Berenson, J.R. NF-kappaB in the pathogenesis and treatment of multiple myeloma. Curr. Opin. Hematol. 2008, 15, 391-399. [CrossRef] [PubMed] 
14. Hideshima, T.; Richardson, P.; Chauhan, D.; Palombella, V.J.; Elliott, P.J.; Adams, J.; Anderson, K.C. The proteasome inhibitor PS-341 inhibits growth, induces apoptosis, and overcomes drug resistance in human multiple myeloma cells. Cancer Res. 2001, 61, 3071-3076.

15. Hideshima, T.; Ikeda, H.; Chauhan, D.; Okawa, Y.; Raje, M.; Podar, K.; Mitsiades, C.; Munshi, N.C.; Richardson, P.G.; Carrasco, R.D. Bortezomib induces canonical nuclear factor-kappaB activation in multiple myeloma cells. Blood 2009, 114, 1046-1052. [CrossRef]

16. Keats, J.J.; Fonseca, R.; Chesi, M.; Schop, R.; Baker, A.; Chng, W.J.; Wier, S.V.; Tiedemann, R.; Shi, C.X.; Sebag, M. Promiscuous mutations activate the noncenonical NF-kappaB pathway in multiple myeloma. Cancer Cell 2007, 12, 131-144. [CrossRef]

17. Mitsiades, N.; Mitsiades, C.S.; Poulaki, V.; Chauhan, D.; Fanourakis, G.; Gu, X.S.; Bailey, C.; Joseph, M.; Libermann, T.A.; Treon, S.P.; et al. Molecular sequelae of proteasome inhibition in human multiple myeloma cells. Proc. Natl. Acad. Sci. USA 2002, 99, 14374-14379. [CrossRef]

18. Hideshima, T.; Mitsiades, C.; Akiyama, M.; Hayashi, T.; Chauhan, D.; Richardson, P.; Schlossman, R.; Podar, K.; Munshi, N.C.; Mitsiades, N.; et al. Molecular mechanisms mediating antimyeloma activety of proteasome inhibitor PS-341. Blood 2003, 101, 1530-1534. [CrossRef]

19. Noborio-Hatano, K.; Kikuchi, J.; Takatoku, M.; Shimizu, R.; Wada, T.; Ueda, M.; Nobuyoshi, M.; Oh, I.; Sato, K.; Suzuki, T.; et al. Bortezomib overcomes cell-adhesion-mediated drug resistance through downregulation of VLA-4 expression in multiple myeloma. Oncogene 2009, 28, 231-242. [CrossRef]

20. Chen, D.; Frezza, M.; Schmitt, S.; Kanwar, J.; Dou, Q.P. Bortezomib as the first proteasome inhibitor anticancer drug: Current status and future perspectives. Curr. Cancer Drug Targets 2011, 11, 239-253. [CrossRef]

21. Boccadoro, M.; Morgan, G.; Cavenagh, J. Preclinical evaluate on of the proteasome inhibitor bortezomib in cancer therapy. Cancer Cell Int. 2005, 5, 18. [CrossRef] [PubMed]

22. Reddy, N.; Czuczman, M.S. Enhancing activity and overcoming chemoresistance in hematologyic malignancies with bortezomib: Preclinical mechanistic studies. Ann. Oncol. 2010, 21, 1756-1764. [CrossRef] [PubMed]

23. Harousseau, J.L.; Attal, M.; Avet-Loiseau, H.; Marit, G.; Caillot, D.; Mohty, M.; Lenain, P.; Hulin, C.; Facon, T.; Casassus, P.; et al. Bortezomib plus dexamethasone is superior to vincristine plus doxorubicin plus dexamethasone as induction treatment prior to autologous stem cell transplantation in newly diagnosed multiple myeloma: Results of the IFM 2005-01 phase III trial. J. Clin. Oncol. 2010, 28, 4621-4629. [CrossRef] [PubMed]

24. Einsele, H.; Engelhardt, M.; Tapprich, C.; Müller, J.; Liebisch, P.; Langer, C.; Kropff, M.; Mügge, L.O.; Jung, W.; Wolf, H.H.; et al. Phase II study of bortezomib, cyclophosphamide and dexamethasone as induction therapy in multiple myeloma: DSMM XI trial. Br. J. Haematol. 2017, 179, 586-597. [CrossRef] [PubMed]

25. Cavo, M.; Tacchetti, P.; Patriarca, F.; Petrucci, M.T.; Pantani, L.; Galli, M.; Di Raimondo, F.; Crippa, C.; Zamagni, E.; Palumbo, A.; et al. Bortezomib with thalidomide plus dexamethasone compared with thalidomide plus dexamethasone as induction therapy before, and consolidation therapy after, double autologous stem-cell transplantation in newly diagnosed multiple myeloma: A randomized phase 3 study. Lancet 2010, 376, 2075-2085. [PubMed]

26. Rosiñol, L.; Oriol, A.; Teruel, A.I.; Hernández, D.; López-Jiménez, J.; de la Rubia, J.; Granell, M.; Besalduch, J.; Palomera, L.; González, Y.; et al. Superiority of bortezomib, thalidomide, and dexamethasone (VTD) as induction pretransplantation therapy in multiple myeloma: Randomized phase 3 PETHEMA/GEM study. Blood 2012, 120, 1589-1596. [CrossRef]

27. Moreau, P.; Hulin, C.; Macro, M.; Caillot, D.; Chaleteix, C.; Roussel, M.; Garderet, L.; Royer, B.; Brechignac, S.; Tiab, M.; et al. VTD is superior to VCD prior to intensive therapy in multiple myeloma: Results of the prospective IFM2013-04 trial. Blood 2016, 127, 2569-2574. [CrossRef]

28. Sonneveld, P.; Schmidt-Wolf, I.G.; van der Holt, B.; El Jarari, L.; Bertsch, U.; Salwender, H.; Zweegman, S.; Vellenga, E.; Broyl, A.; Blau, I.W.; et al. Bortezomib induction and maintenance treatment in patients with newly diagnosed multiple myeloma: Results of the randomized phase III HOVON-65/GMMG-HD4 trial. J. Clin. Oncol. 2012, 30, 2946-2955. [CrossRef]

29. Attal, M.; Lauwers-Cances, V.; Hulin, C.; Leleu, X.; Caillot, D.; Escoffre, M.; Arnulf, B.; Macro, M.; Belhadj, K.; Garderet, L.; et al. Lenalidomide, bortezomib, and dexamethasone with transplantation for myeloma. $N$. Engl. J. Med. 2017, 376, 1311-1320. [CrossRef] 
30. Moreau, P.; Attal, M.; Hulin, C.; Arnulf, B.; Belhadj, K.; Benboubker, L.; Béné, M.C.; Broijl, A.; Caillon, H.; Caillot, D.; et al. Bortezomib, thalidomide, and dexamethasone with or without daratumumab before and after autologous stem-cell transplantation for newly diagnosed multiple myeloma (Cassiopeia): A randomized, open-label, phase 3 study. Lancet 2019, 394, 29-38. [CrossRef]

31. Corso, A.; Barbarano, L.; Mangiacavalli, S.; Spriano, M.; Alessandrino, E.P.; Cafro, A.M.; Pascutto, C.; Varettoni, M.; Bernasconi, P.; Grillo, G.; et al. Bortezomib plus dexamethasone can improve stem cell collection and overcome the need for additional chemotherapy before autologous transplant in patients with myeloma. Leuk. Lymphoma 2010, 51, 236-242. [CrossRef] [PubMed]

32. Harousseau, J.L.; Attal, M.; Leleu, X.; Troncy, J.; Pegourie, B.; Stoppa, A.M.; Hulin, C.; Benboubker, L.; Fuzibet, J.G.; Renaud, M.; et al. Bortezomib plus dexamethasone as induction treatment prior to autologous stem cell transplantation in patients with newly diagnosed multiple myeloma: Results of an IFM phase II study. Haematologica 2006, 91, 1498-1505. [PubMed]

33. Jagannath, S.; Durie, B.G.; Durie, B.G.; Wolf, J.L.; Camacho, E.S.; Irwin, D.; Lutzky, J.; McKinley, M.; Potts, P.; Gabayan, A.E.; et al. Extended follow-up of a phase 2 trial of bortezomib alone and in combination with dexamethasone for the frontline treatment of multiple myeloma. Br. J. Haematol. 2009, 146, 619-626. [CrossRef] [PubMed]

34. Kropff, M.; Bisping, G.; Schuck, E.; Liebisch, P.; Lang, N.; Hentrich, M.; Dechow, T.; Kröger, N.; Salwender, H.; Metzner, B.; et al. Bortezomib in combination with intermediate-dose dexamethasone and continuous low-dose oral cyclophosphamide for relapsed multiple myeloma. Br. J. Haematol. 2007, 138, 330-337. [CrossRef] [PubMed]

35. Ahn, J.S.; Yang, D.H.; Jung, S.H.; Park, H.C.; Moon, J.H.; Sohn, S.K.; Bae, S.Y.; Kim, Y.K.; Kim, H.J.; Lee, J.J. A comparison of bortezomib, cyclophosphamide, and dexamethasone (Vel-CD) chemotherapy without and with thalidomide (Vel-CTD) for the treatment of relapsed or refractory multiple myeloma. Ann. Hematol. 2012, 91, 1023-1030. [CrossRef]

36. Fu, W.; Delasalle, K.; Wang, J.; Song, S.; Hou, J.; Alexanian, R.; Wang, M. Bortezomib-cyclophosphamide-dexamethasone for relapsing multiple myeloma. Am. J. Hematol. 2012, 35, 562-565. [CrossRef]

37. Bensinger, W.I.; Jagannath, S.; Vescio, R.; Camacho, E.; Wolf, J.; Irwin, D.; Capo, G.; McKinley, M.; Potts, P.; Vesole, D.H.; et al. Phase 2 study of two sequential three drug combinations containing bortezomib, cyclophosphamide and dexamethasone, followed by bortezomib, thalidomide and dexamethasone as frontline therapy for multiple myeloma. Br. J. Haematol. 2010, 148, 562-568. [CrossRef]

38. Reeder, C.B.; Reece, D.E.; Kukreti, V.; Chen, C.; Trudel, S.; Laumann, K.; Hentz, J.; Pirooz, N.A.; Piza, J.G.; Tiedemann, R.; et al. Once-versus twice-weekly bortezomib induction therapy with CyBorD in newly diagnosed multiple myeloma. Blood 2010, 115, 3416-3417. [CrossRef]

39. Kumar, S.; Flinn, I.; Richardson, P.G.; Hari, P.; Callander, N.; Noga, S.J.; Stewart, A.K.; Turturro, F.; Rifkin, R.; Wolf, J.; et al. Randomized, multicenter, phase 2 study (EVOLUTION) of combinations of bortezomib, dexamethasone, cyclophosphamide, and lenalidomide in previously untreated multiple myeloma. Blood 2012, 119, 4375-4382. [CrossRef]

40. Reeder, C.B.; Reece, D.E.; Kukreti, V.; Chen, C.; Trudel, S.; Hentz, J.; Noble, B.; Pirooz, N.A.; Spong, J.E.; Piza, J.G.; et al. Cyclophosphamide, bortezomib and dexamethasone induction for newly diagnosed multiple myeloma: High response rates in a phase II clinical trial. Leukemia 2009, 23, 1337-1341. [CrossRef]

41. Khan, M.L.; Reeder, C.B.; Kumar, S.K.; Lacy, M.Q.; Reece, D.E.; Dispenzieri, A.; Gertz, M.A.; Greipp, P.; Hayman, P.; Zeldenhurst, S.; et al. A comparison of lenalidomide/dexamethasone versus cyclophosphamide/lenalidomide/dexamethasone versus cyclophosphamide/bortezo -mib/dexamethasone in newly diagnosed multiple myeloma. Br. J. Haematol. 2012, 156, 326-333. [CrossRef] [PubMed]

42. Richardson, P.G.; Weller, E.; Lonial, S.; Jakubowiak, A.J.; Jagannath, S.; Raje, N.S.; Avigan, D.E.; Xie, W.; Ghobrial, I.M.; Schlossman, R.L.; et al. Lenalidomide, bortezomib, and dexamethasone combination therapy in patients with newly diagnosed multiple myeloma. Blood 2010, 116, 679-686. [CrossRef] [PubMed]

43. Rosiñol, L.; Oriol, A.; Rios, R.; Sureda, A.; Blanchard, M.J.; Hernández, M.T.; Martínez-Martínez, R.; Moraleda, J.M.; Jarque, I.; Bargay, J.; et al. Bortezomib, lenalidomide, and dexamethasone as induction therapy prior to autologous transplant in multiple myeloma. Blood 2019, 134, 1337-1345. [CrossRef] [PubMed] 
44. San Miguel, J.F.; Schlag, R.; Khuageva, N.K.; Dimopoulos, M.A.; Shpilberg, O.; Kropff, M.; Spicka, I.; Petrucci, M.T.; Palumbo, A.; Samoilova, O.S.; et al. Bortezomib plus melphalan and prednisone for initial treatment of multiple myeloma. N. Engl. J. Med. 2008, 359, 906-917. [CrossRef]

45. Mateos, M.V.; Dimopoulos, M.A.; Cavo, M.; Suzuki, K.; Jakubowiak, A.; Knop, S.; Doyen, C.; Lucio, P.; Nagy, Z.; Kaplan, P.; et al. Daratumumab plus bortezomib, melphalan, and prednisone for untreated myeloma. N. Engl. J. Med. 2018, 378, 518-528. [CrossRef]

46. Durie, B.G.M.; Hoering, A.; Abidi, M.H.; Rajkumar, S.V.; Epstein, J.; Kahanic, S.P.; Thakuri, M.; Reu, F.; Reynolds, C.M.; Sexton, R.; et al. Bortezomib with lenalidomide and dexamethasone versus lenalidomide and dexamethasone alone in patients with newly diagnosed myeloma without intent for immediate autologous stem-cell transplant (SWOG S0777): A randomized, open-label, phase 3 trial SWOG S0777. Lancet 2017, 389, 519-527.

47. O’Donnell, E.K.; Laubach, J.P.; Yee, A.J.; Chen, T.; Huff, C.A.; Basile, F.G.; Wade, P.M.; Paba-Prada, C.E.; Ghobrial, I.M.; Schlossman, R.L.; et al. A phase 2 study of modified lenalidomide, bortezomib and dexamethasone in transplant-ineligible multiple myeloma. Br. J. Haematol. 2018, 182, 222-230. [CrossRef]

48. Mitsiades, N.; Mitsiades, C.S.; Richardson, P.G.; Poulaki, V.; Tai, Y.T.; Chauhan, D.; Fanourakis, G.; Gu, X.; Bailey, C.; Joseph, M.; et al. The proteasome inhibitor PS-341 potentiates sensitivity of multiple myeloma cells to conventional chemotherapeutic agents: Therapeutic applications. Blood 2003, 101, 2377-2380. [CrossRef]

49. Mateos, M.V.; Hernández, J.M.; Hernández, M.T.; Gutiérrez, N.C.; Palomera, L.; Fuertes, M.; Díaz-Mediavilla, J.; Lahuerta, J.J.; de la Rubia, J.; Terol, M.J.; et al. Bortezomib plus melphalan and prednisone in elderly untreated patients with multiple myeloma: Results of a multicenter phase $1 / 2$ study. Blood 2006, 108, 2165-2172. [CrossRef]

50. Mateos, M.V.; Hernández,J.M.; Hernández, M.T.; Gutiérrez, N.C.; Palomera, L.; Fuertes, M.; Garcia-Sanchez, P.; Lahuerta, J.J.; de la Rubia, J.; Terol, M.J.; et al. Bortezomib plus melphalan and prednisone in elderly untreated patients with multiple myeloma: Updated time-to events results and prognostic factors for time to progression. Haematologica 2008, 93, 560-565. [CrossRef]

51. Mateos, M.V.; Richardson, P.G.; Schlag, R.; Khuageva, N.K.; Dimopoulos, M.A.; Shpilberg, O.; Kropff, M.; Spicka, I.; Petrucci, M.T.; Palumbo, A.; et al. Bortezomib plus melphalan and prednisone compared with melphalan and prednisone in previously untreated multiple myeloma: Updated follow-up and impact of subsequent therapy in the VISTA trial. J. Clin. Oncol. 2010, 28, 2259-2266. [CrossRef] [PubMed]

52. De Weers, M.; Tai, Y.T.; van der Veer, M.S.; Bakker, J.M.; Vink, T.; Jacobs, D.C.; Oomen, L.A.; Peipp, M.; Valerius, T.; Slootstra, J.W.; et al. Daratumumab, a novel therapeutic human CD38 monoclonal antibody, induces killing of multiple myeloma and other hematological tumors. J. Immunol. 2011, 186, 1840-1848. [CrossRef] [PubMed]

53. Overdijk, M.B.; Verploegen, S.; Bögels, M.; van Egmond, M.; Lammerts van Bueren, J.J.; Mutis, T.; Groen, R.W.; Breij, E.; Martens, A.C.; Bleeker, W.K.; et al. Antibody-mediated phagocytosis contributes to the anti-tumor activity of the therapeutic antibody daratumumab in lymphoma and multiple myeloma. $m A b s$ 2015, 7, 311-321. [CrossRef] [PubMed]

54. Overdijk, M.B.; Jansen, J.H.; Nederend, M.; Lammerts van Bueren, J.J.; Groen, R.W.; Parren, P.W.; Leusen, J.H.; Boross, P. The therapeutic CD38 monoclonal antibody daratumumab induces programed cell death via Fcgamma receptor-mediated cross-linking. J. Immunol. 2016, 197, 807-813. [CrossRef]

55. Van Bueren, J.L.; Jakobs, D.; Kaldenhoven, N.; Roza, M.; Hiddingh, S.; Meesters, J.I.; Voorhorst, M.; Gresnigt, E.; Wiegman, L.; Buijsse, A.O.; et al. Direct in vitro comparison of daratumumab with surrogate analogs of CD38 antibodies MOR03087, SAR650984 and Ab79. Blood 2014, 124, 3274.

56. Krejcik, J.; Casneuf, T.; Nijhof, I.S.; Verbist, B.; Bald, J.; Plesner, T.; Syed, K.; Liu, K.; van de Donk, N.W.; Weiss, B.M.; et al. Daratumumab depletes CD38+ immune regulatory cells, promotes T-cell expansion, and skews T-cell repertoire in multiple myeloma. Blood 2016, 128, 384-394. [CrossRef]

57. Chiu, C.; Casneuf, T.; Axel, A.E.; Lysaght, A.C.; Bald, J.; Khokhar, M.Z.; Plesner, P.; Usmani, S.Z.; Goldschmidt, H.; Ahmadi, T.; et al. Daratumumab in combination with lenalidomide plus dexamethasone induces clonality increase and T-cell exapansion: Results from a phase 3 randomized study (POLLUX). Blood 2016, 128, 4531. [CrossRef] 
58. Adams, H.C., III; Stevenaert, F.; Krejcik, J.; Van der Borght, K.; Smets, T.; Bald, J.; Abraham, Y.; Ceulemans, H.; Chiu, C.; Vanhoof, G.; et al. High-parameter mass cytometry evaluate on of relapsed/refractory multiple myeloma patients treated with daratumumab demonstrates immune modulation as a novel mechanism of action. Cytometry. A 2019, 95, 279-289. [CrossRef]

59. Mitsiades, N.; Mitsiades, C.S.; Poulaki, V.; Chauhan, D.; Richardson, P.G.; Hideshima, T.; Munshi, N.C.; Treon, S.P.; Anderson, K.C. Apoptotic signaling induced by immunomodulatory thalidomide analogs in human multiple myeloma cells: Therapeutic implications. Blood 2002, 99, 4525-4530. [CrossRef]

60. Efentakis, P.; Kremastiotis, G.; Varela, A.; Nikolaou, P.E.; Papanagnou, E.D.; Davos, C.H.; Tsoumani, M.; Agrogiannis, G.; Konstantinidou, A.; Kastritis, E.; et al. Molecular mechanism of carfilzomib-induced cardiotoxicity in mice and the emerging cardioprotective role of metformin. Blood 2019, 133, 710-723. [CrossRef]

61. Dimopoulos, M.A.; Moreau, P.; Palumbo, A.; Joshua, D.; Pour, L.; Hájek, R.; Facon, T.; Ludwig, H.; Oriol, A.; Goldschmidt, H.; et al. Carfilzomib and dexamethasone versus bortezomib and dexamethasone for patients with relapsed or refractory multiple myeloma (endeavor): A randomized phase 3, open-label, multicenter study. Lancet Oncol. 2016, 17, 27-38. [CrossRef]

62. Moreau, P.; Mateos, M.V.; Berenson, J.R.; Weisel, K.; Lazzaro, A.; Song, K.; Dimopoulos, M.A.; Huang, M.; Zahlten-Kumeli, A.; Stewart, A.K. Once weekly versus twice weekly carfilzomib dosing in patients with relapsed and refractory multiple myeloma (A.R.R.O.W.): Interim analysis results of a randomized, phase 3 study. Lancet Oncol. 2018, 19, 953-964. [CrossRef]

63. Stewart, A.K.; Rajkumar, S.V.; Dimopoulos, M.A.; Masszi, T.; Špička, I.; Oriol, A.; Hájek, R.; Rosiñol, L.; Siegel, D.S.; Mihaylov, G.G.; et al. Carfilzomib, lenalidomide, and dexamethasone for relapsed multiple myeloma. N. Engl. J. Med. 2015, 372, 142-152. [CrossRef] [PubMed]

64. Chari, A.; Martinez-Lopez, J.; Mateos, M.V.; Bladé, J.; Benboubker, L.; Oriol, A.; Arnulf, B.; Rodriguez-Otero, P.; Pineiro, L.; Jakubowiak, A.; et al. Daratumumab plus carfilzomib and dexamethasone in patients with relapsed or refractory multiple myeloma. Blood 2019, 134, 421-431. [CrossRef]

65. Moreau, P.; Masszi, T.; Grzasko, N.; Bahlis, N.J.; Hansson, M.; Pour, L.; Sandhu, I.; Ganly, P.; Baker, B.W.; Jackson, S.R.; et al. Oral ixazomib, lenalidomide, and dexamethasone for multiple myeloma. N. Engl. J. Med. 2016, 374, 1621-1634. [CrossRef] [PubMed]

66. Papadopoulos, K.P.; Siegel, D.S.; Vesole, D.H.; Lee, P.; Rosen, S.T.; Zojwalla, N.; Holahan, J.R.; Lee, S.; Wang, Z.; Badros, A. Phase 1 study of 30-minute infusion of carfilzomib as single agent or in combination with low-dose dexamethasone in patients with relapsed and or refractory multiple myeloma. J. Clin. Oncol. 2015, 33, 732-739. [CrossRef]

67. Lendvai, N.; Hilden, P.; Devlin, S.; Landau, H.; Hassoun, H.; Lesokhin, A.M.; Tsakos, I.; Redling, K.; Koehne, G.; Chung, D.J.; et al. A phase 2 single-center study of carfilzomib $56 \mathrm{mg} / \mathrm{m} 2$ with or without low-dose dexamethasone in relapsed multiple myeloma. Blood 2014, 124, 899-906. [CrossRef]

68. Berenson, J.R.; Cartmell, A.; Bessudo, A.; Lyons, R.M.; Harb, W.; Tzachanis, D.; Agajanian, R.; Boccia, R.; Coleman, M.; Moss, R.A.; et al. CHAMPION-1: A phase 1/2 study of once-weekly carfilzomib and dexamethasone for relapsed or refractory multiple myeloma. Blood 2016, 127, 3360-3368. [CrossRef]

69. Niesvizky, R.; Martin, T.G.; Bensinger, W.I.; Alsina, M.; Siegel, D.S.; Kunkel, L.A.; Wong, A.F.; Lee, S.; Orlowski, R.Z.; Wang, M. Phase Ib dose-escalation study (PX-171-006) of carfilzomib, lenalidomide, and low-dose dexamethasone in relapsed or progressive multiple myeloma. Clin. Cancer Res. 2013, 19, 2248-2256. [CrossRef]

70. Wang, M.; Martin, T.; Bensinger, W.; Alsina, M.; Siegel, D.S.; Kavalerchik, E.; Huang, M.; Orlowski, R.Z.; Niesvizky, R. Phase 2 dose-expansion study (PX-171-006) of carfilzomib, lenalidomide, and low-dose dexamethasone in relapsed or progressive multiple myeloma. Blood 2013, 122, 3122-3128. [CrossRef]

71. Tzogani, K.; Florez, B.; Markey, G.; Caleno, M.; Olimpieri, O.M.; Melchiorri, D.; Hovgaard, D.J.; Sarac, S.B.; Penttilä, K.; Lapveteläinen, T.; et al. European Medicines Agency review of ixazomib (Ninlaro) for the treatment of adult patients with multiple myeloma who have received at least one prior therapy. ESMO Open 2019, 4, e000570. [CrossRef] [PubMed] 
72. Attal, M.; Lauwers-Cances, V.; Marit, G.; Caillot, D.; Moreau, P.; Facon, T.; Stoppa, A.M.; Hulin, C.; Benboubker, L.; Garderet, L.; et al. Lenalidomide maintenance after stem-cell transplantation for multiple myeloma. N. Engl. J. Med. 2012, 366, 1782-1791. [CrossRef] [PubMed]

73. McCarthy, P.L.; Owzar, K.; Hofmeister, C.C.; Hurd, D.D.; Hassoun, H.; Richardson, P.G.; Giralt, S.; Stadtmauer, E.A.; Weisdorf, D.J.; Vij, R.; et al. Lenalidomide after stem-cell transplantation for multiple myeloma. N. Engl. J. Med. 2014, 366, 895-905. [CrossRef] [PubMed]

74. Palumbo, A.; Cavallo, F.; Gay, F.; Di Raimondo, F.; Ben Yehuda, D.; Petrucci, M.T.; Pezzatti, S.; Caravita, T.; Cerrato, C.; Ribakovsky, E.; et al. Autologous transplantation and maintenance therapy in multiple myeloma. N. Engl. J. Med. 2014, 371, 895-905. [CrossRef]

75. Palumbo, A.; Hajek, R.; Delforge, M.; Kropff, M.; Petrucci, M.T.; Catalano, J.; Gisslinger, H.; Wiktor-Jędrzejczak, W.; Zodelava, M.; Weisel, K.; et al. Continuous lenalidomide treatment for newly diagnosed multiple myeloma. N. Engl. J. Med. 2012, 366, 1759-1769. [CrossRef]

76. McCarthy, P.L.; Holstein, S.A.; Petrucci, M.T.; Richardson, P.G.; Hulin, C.; Tosi, P.; Bringhen, S.; Musto, P.; Anderson, K.C.; Caillot, D.; et al. Lenalidomide maintenance after autologous stem-cell transplantation in newly diagnosed multiple myeloma: A meta-analysis. J. Clin. Oncol. 2017, 35, 3279-3289. [CrossRef]

77. Goldschmidt, H.; Lokhorst, H.M.; Mai, E.K.; van der Holt, B.; Blau, I.W.; Zweegman, S.; Weisel, K.C.; Vellenga, E.; Pfreundschuh, M.; Kersten, M.J.; et al. Bortezomib before and after high-dose therapy in myeloma: Long-term results from the phase III HOVON-65/GMMG-HD4 trial. Leukemia 2018, 32, 383-390. [CrossRef]

78. Isoda, A.; Murayama, K.; Ito, S.; Kohara, Y.; Iino, M.; Miyazawa, Y.; Matsumoto, M.; Handa, H.; Imai, Y.; Ishiguro, T.; et al. Bortezomib maintenance therapy in transplant-ineligible myeloma patients who plateaued after bortezomib-based induction therapy: A multicenter phase II clinical trial. Int. J. Hematol. 2018, 108, 39-46. [CrossRef]

79. Gupta, N.; Yang, H.; Hanley, M.J.; Zhang, S.; Liu, R.; Kumar, S.; Richardson, P.G.; Skacel, T.; Venkatakrishnan, K. Dose and schedule selection of the oral proteasome inhibitor ixazomib in relapsed/refractory multiple myeloma: Clinical and model-based analyses. Target Oncol. 2017, 12, 643-654. [CrossRef]

80. Dimopoulos, M.A.; Gay, F.; Schjesvold, F.; Beksac, M.; Hajek, R.; Weisel, K.C.; Goldschmidt, H.; Maisnar, V.; Moreau, P.; Min, C.K.; et al. Oral ixazomib maintenance following autologous stem cell transplantation (TOURMALINE-MM3): A double-blind, randomized, placebo-controlled phase 3 trial. Lancet 2019, 393, 253-264. [CrossRef]

81. Colland, F. The therapeutic potential of deubiquitinating enzyme inhibitors. Biochem. Soc. Trans. 2010, 38, 137-143. [CrossRef] [PubMed]

82. Schwickart, M.; Huang, X.; Lill, J.R.; Liu, J.; Ferrando, R.; French, D.M.; Maecker, H.; O’Rourke, K.; Bazan, F.; Eastham-Anderson, J.; et al. Deubiquitinase USP9X stabilizes MCL1 and promotes tumour cell survival. Nature 2010, 463, 103-107. [CrossRef] [PubMed]

83. Nijman, S.M.B.; Luna-Vargas, M.P.; Velds, A.; Brummelkamp, T.R.; Dirac, A.M.; Sixma, T.K.; Bernards, R. A genomic and functional inventory of deubiquitinating enzymes. Cell 2005, 123, 773-786. [CrossRef] [PubMed]

84. Chauhan, D.; Tian, Z.; Nicholson, B.; Kumar, K.G.; Zhou, B.; Carrasco, R.; McDermott, J.L.; Leach, C.A.; Fulcinniti, M.; Kodrasov, M.P.; et al. A small molecule inhibitor of ubiquitin-specific protease-7 induces apoptosis in multiple myeloma cells and overcomes bortezomib resistance. Cancer Cell 2012, 22, 345-358. [CrossRef] [PubMed]

85. Li, J.; Yakushi, T.; Parlati, F.; Mackinnon, A.L.; Perez, C.; Ma, Y.; Carter, K.P.; Colayco, S.; Magnuson, G.; Brown, B.; et al. Capzimin is a potent and specific inhibitor of proteasome isopeptidase Rpn11. Nat. Chem. Biol. 2017, 13, 486-493. [CrossRef] [PubMed]

86. Song, Y.; Li, S.; Ray, A.; Das, D.S.; Qi, J.; Samur, M.K.; Tai, Y.T.; Munshi, N.; Carrasco, R.D.; Chauhan, D.; et al. Blockade of deubiquitylating enzyme Rpn11 triggers apoptosis in multiple myeloma cells and overcomes bortezomib resistance. Oncogene 2017, 36, 5631-5638. [CrossRef] [PubMed]

87. Lauinger, L.; Li, J.; Shostak, A.; Cemel, I.A.; Ha, N.; Zhang, Y.; Merkl, P.E.; Obermeyer, S.; Stankovic-Valentin, N.; Schafmeier, T.; et al. Thiolutin is a zinc chelator that inhibits the Rpn11 and other JAMM metalloproteases. Nat. Chem. Biol. 2017, 13, 709-714. [CrossRef] 
88. Pawlyn, C.; Davies, F.; Cairns, D.; Striha, A.; Hockaday, A.; Kishore, B.; Garg, M.; Williams, C.; Karunanithi, K.; Lindsay, J.; et al. Quadruplet KCRD (carfilzomib, cyclophosphamide, lenakidomide and dexamethasone) induction for newly diagnosed myeloma patients:abstract OAB-002. In Proceedings of the 17th International Myeloma Workshop, Boston, MA, USA, 12-15 September 2019.

89. Voorhees, P.; Kaufman, J.L.; Laubach, J.; Sborov, D.; Reeves, B.; Rodriguez, C.; Chari, A.; Silbermann, R.; Costa, L.; Anderson, L.; et al. Daratumumab + lenalidomide, bortezomib \& dexamtehsone improved depth of response in transplant-eligible newly diagnosed multiple myeloma: GRIFFIN:abstract OAB-087. In Proceedings of the 17th International Myeloma Workshop, Boston, MA, USA, 12-15 September 2019.

(C) 2020 by the author. Licensee MDPI, Basel, Switzerland. This article is an open access article distributed under the terms and conditions of the Creative Commons Attribution (CC BY) license (http://creativecommons.org/licenses/by/4.0/). 